\title{
Henri Bergson, neotomismo y filosofía de la libertad en Tomás de Aquino
}

\author{
SANTIAGO ARGÜELLO* \\ CONICET - Universidad Católica Argentina (Argentina) \\ yagoarg@yahoo.com.ar \\ Álvaro CORTINA** \\ Universidad Diego Portales (Chile) \\ alvarocortina@hotmail.com
}

\begin{abstract}
Resumen
Observando la considerable presencia de la filosofía de Henri Bergson en algunos destacados intérpretes de la filosofía de Tomás de Aquino a lo largo del s. XX, cabe conjeturar una influencia indirecta del autor francés en la renovación de las investigaciones sobre el predicho autor medieval, particularmente en lo que se refiere a la cuestión de la libertad. A fin de determinar esta cuestión, se pasa revista a la relación establecida en el seno del neotomismo entre Bergson y el Aquinate. Por último, se ensaya una relectura en la obra de Tomás de Aquino de la relación entre inteligencia y voluntad como configuradora del ser libre, teniendo en cuenta algunas inquietudes metafísicas planteadas al respecto por el moderno pensador francés.
\end{abstract}

Palabras clave: Tomás de Aquino, Bergson, neotomismo, libertad.

\section{Bergson, Neo-Thomism and Aquinas' Theory of Freedom}

\begin{abstract}
Checking the clear presence of Bergson in some important interpreters of Thomas Aquinas along the 20th century, certain influence from the French writer can be suspected in the renewal of Thomism; particularly, regarding the question of freedom. In order to determine the issue, the present study examines the relationship between Bergson and Aquinas according established within the Neo-Thomism. Lastly, taking into account some metaphysical concerns raised by Bergson, it takes place a re-reading of the relationship between intelligence and will in Aquinas' works. For in this relationship appears the shape of freedom.
\end{abstract}

Key words: Thomas Aquinas, Bergson, Neo-Thomism, Freedom.

\footnotetext{
* Doctor en Filosofía por la Universidad de Navarra (España) y Licenciate in Mediaeval Studies por el Pontifical Institute of Mediaeval Studies (Canadá). Entre sus publicaciones cabe mencionar el libro Posibilidad y principio de plenitud en Tomás de Aquino (2005), así como los artículos "Polisemia del término potencia en la filosofía tomística de la mente" (2014) y "Tomás, Aristóteles y la creación. Un enfoque desde la teoría modal" (2014).

** Licenciado en Filosofía por la Universidad de Navarra (España), Máster en Estudios Avanzados de Filosofía por la Universidad Complutense de Madrid (España). Programa de doctorado en Filosofía UDP-Leiden (Chile). Entre sus publicaciones cabe mencionar el artículo "García Morente y el entusiasmo generacional por Henri Bergson” (2012).
} 


\section{Introducción}

Uno de los pensadores que más influencia tuvo sobre los intérpretes más destacados de Tomás de Aquino en la primera mitad del siglo XX, fue el ganador del premio Nobel de literatura de 1927, Henri Bergson. Entre sus discípulos y/o atentos lectores tomistas, cabe contar a Antonin-Dalmace Sertillanges, Réginald Garrigou-Lagrange, Jacques Maritain, Étienne Gilson, además de otros autores -más recientes- afines de alguna manera al pensamiento del Aquinate, como Henri Gouhier, Vittorio Mathieu o Leonardo Polo, entre otros. Es indiscutible que la figura de Bergson ha contribuido, aunque de forma indirecta y en algunos casos negativa, a la renovación del pensamiento tomista. Por lo demás, nuestra intención es sugerir que, en orden a proseguir interpretando la filosofía del Aquinate, la inspiración que surge del un tanto olvidado bergsonismo no se ha agotado aún. Siguiendo a Mathieu (1980: 41), cabe afirmar que, a primera vista, el pensamiento bergsoniano aparece construido según los moldes tradicionales. Pero, al mismo tiempo, ya es posible atisbar en él una nueva dinámica de la que sería provechoso extraer una mayor libertad y originalidad de pensamiento.

La posición de Bergson volvió a hacer presente de forma original un problema importantísimo, incluso al margen de si haya sabido acertar en la solución: «el problema de la libertad» (Mathieu, 1980: 49). La cuestión de la libertad es, junto con el de la duración, la primera de las que Bergson aborda en su carrera, en su Essai sur les donées immédiates de la conscience, de 1889. En este sentido, esta cuestión no es susceptible de ser considerada como derivada, secundaria o externa a su filosofía. En este primer ensayo, presentado junto con la tesis latina Quid Aristoteles de loco senserit, tenemos toda la doctrina de Bergson in nuce, como ha afirmado Juan Miguel Palacios (2006: 9). De este modo, el nombre de Bergson va indisolublemente asociado a una filosofía de la libertad. Ahora bien, el enfoque adoptado por él ante tan magno asunto fue el de cierta oposición al intelectualismo y finalismo. Tan es así que el distinguido pensador francés «comenzó a aparecer a los ojos del público como el filósofo de lo indefinido, de la ausencia de contornos, de un devenir sin sustancia. El gusto de la época, que empezaba a apreciar el impresionismo, hizo de la filosofía de Bergson una especie de impresionismo filosófico» (Mathieu, 1980: 49-50). No es difícil, ciertamente, advertir que el entendimiento de la noción de libertad depende ineluctablemente de cómo se entienda la naturaleza de la inteligencia.

A partir de lo dicho, cabe advertir entonces que la perspectiva hermenéutica adoptada en este trabajo es la de observar la relación de mayor o menor deuda que la interpretación de la filosofía de Tomás de Aquino 
y particularmente el neotomismo contrae con el pensamiento de Henri Bergson; sobre todo en lo tocante a entender mejor la ordenación entre libertad e inteligencia. En resumidas cuentas, se tratará de registrar la valoración más o menos positiva o negativa que el neotomismo ha elaborado en torno a la relación de inteligencia y voluntad propuesta por Bergson.

En la primera parte del trabajo - acápites 1-3 - se abordará la relación entre el neotomismo y Bergson. Algunos de los neotomistas, como Garrigou-Lagrange y Maritain, opinaban que Bergson no sabía ofrecer una solución filosófica satisfactoria al problema de la libertad. No obstante, el segundo de ellos concedía que en el fondo de esa filosofía se halla una búsqueda genuina y valiosa de dicha solución. Para otros, como Charles Péguy, y, particularmente, Sertillanges, Bergson era, como había sido el Aquinate, un auténtico «filósofo de la libertad»; un defensor del espíritu en el pleno sentido de la palabra. Por último, el signo de la valoración de Bergson por parte de Jacques Chevalier y Étienne Gilson, no queda finalmente del todo clara. La incertidumbre judicativa de esta postura puede verse como un utópico intento de transacción con el pensamiento moderno, que intenta equiparar equívocamente la filosofía moderna de Henri Bergson a la clásica de Aristóteles; o bien como una expresión de la más fina retórica que coopera en la comprensión de esa misteriosa búsqueda bergsoniana ya advertida por Maritain. Como intentaremos mostrar, en los tres casos, la dinámica hermenéutica ofrece como resultado final una valoración más positiva que negativa de la filosofía de Bergson.

En la segunda parte, a partir del acápite 4., se abordará una lectura de la obra de Tomás de Aquino en torno a la relación entre inteligencia y libertad, a la vista de las inquietudes que la obra de Bergson en alguna forma nos inspira.

\section{Bergsonismo de faity bergsonismo d'intention según Maritain}

Pocos como Maritain conocieron con tanta profundidad e integridad el pensamiento de Bergson. Su esquema de interpretación dividido en «bergsonismo de hecho»y «bergsonismo de intención» hunde raíces en su experiencia como alumno de Bergson en el Collège de France. Este esquema aparece en la primera obra que le dedicara Maritain: La philosophie bergsonienne, en 1913, la cual -en palabras del mismo Maritain (1983: 75) treinta años más tarde- se erigía en una severa crítica a la filosofía exa- 
minada ${ }^{1}$. «Bergsonismo de hecho», blanco de todas las críticas en esa obra, alude en síntesis a la orientación panteísta y monista inherente a la metafísica bergsoniana, que Maritain (1983: 40) veía terminar en una suerte de spinozismo al revés (al margen: no es casual en este sentido que la afición por Spinoza y Bergson hayan confluido en uno de los pensadores más sobresalientes de la segunda mitad del s. XX, Gilles Deleuze). Por supuesto, era claro que conforme a esta manera de pensar, no había mucho espacio para la libertad; ni para la razón. En lo que respecta a esta última, todo el sistema bergsoniano se encontraba, según Maritain, lastrado de irracionalidad. Él hace ver que, como antes Tomás, Bergson afirma una novedad óntica más allá de lo cuantitativo y del número, una conciencia espontánea y una connaturalidad entre la inteligencia y la materialidad (Maritain, 1986: 475-479). Sin embargo, al mismo tiempo advertía que, a diferencia de Bergson, quien partía de una noción empobrecida de inteligencia, como algo pasivo y formal, en parte heredado de los filósofos a los que pretendía superar -Spencer y Kant-, Tomás de Aquino reconoce en la inteligencia un carácter trascendente a la matemática y el espacio. En lo que respecta a la concepción y formulación de la libertad propia del «bergsonismo de hecho», Maritain (1986: 471) señala que en Bergson «la libertad se confunde con la contingencia o con la espontaneidad». En efecto, Bergson (1959a: 192) había definido la libertad como una relación estrictamente indefinible entre el yo concreto y el acto que realiza -indefinible ya que, según él, toda definición, análisis de partes, comportaría espacialización; lo que cae fuera de la libertad.

Por su parte, «bergsonismo de intención» aludía a todos aquellos componentes que, según Maritain, se orientaban a la sabiduría tomista. En efecto, Maritain (1983: 41) consideraba a su vez que la filosofía de Bergson era capaz de intuir o entrever la espiritualidad y libertad del alma y la realidad de un Dios personal: podía hacerlo, pero sin ser capaz todavía de una elaboración filosófica adecuada acerca de dichas realidades. Por ello, al analizar ambas orientaciones radicales del pensamiento de Bergson, Maritain (1983: 72) llega a considerar que si «los peligros del

\footnotetext{
$1 \quad \mathrm{Al}$ margen de los matices, entre las dos obras de Maritain dedicadas a Bergson, no hay verdadero cambio de perspectiva. A lo más, tal vez el paso de los años hizo que en 1944 Maritain mostrara un estilo menos polémico. Por lo demás, no deja de ser interesante registrar aquí la impresión que causara en Léon Bloy —otro maestro de Maritainla crítica a Bergson por parte de su 'ahijado' (como le llama a Maritain), la cual fue publicándose en artículos hasta reunirse finalmente en 1913 en La philosophie bergsonienne. En la entrada del 17 de octubre de 1912 de sus Diarios, Bloy escribía: «He leído en la Revue Thomiste un artículo de mi ahijado Jacques Maritain: "Los dos bergsonismos" (...). Con una precisión y una fuerza verdaderamente terribles, Jacques Maritain denuncia "el connatural orgullo" que padece la filosofía» (Bloy, 2007).
} 
panteísmo son inherentes a la metafísica bergsoniana, él, Bergson, eligió deliberadamente contra el panteísmo». En vez de aferrarse al spinozismo, su orientación fue hacia el espiritualismo y personalismo.

La consecuencia que Maritain (1983: 40-41) deduce de todo esto es la siguiente: «la cuestión consiste en saber si su metafísica lo ayudó en esto; o si, en cierto modo no ha triunfado él mismo de su propia metafísica y si entre posibilidades de desarrollo muy diferentes y aún opuestas (...), no son factores extra filosóficos los que lo han hecho optar». Maritain va a concluir que el Bergson de la libertad es el Bergson personal -biográfico, no el Bergson filosófico y literal. Como ya señalara en su estudio de 1913, Maritain (1986: 89) opina que Bergson no quiso ser panteísta, pero que tampoco llegó a establecer una distinción clara y esencial entre Dios y la Naturaleza. De este modo, si Bergson pudo superar los problemas a los que su propio pensamiento le arrastró por lógica intrínseca, no fue con la ayuda de su propia filosofía; ni siquiera con la filosofía de otro. Según Maritain (1983: 72), si Bergson se aproximó en su vejez más y más al catolicismo (lo que su testamento cristaliza), no fue por una original afinidad de su pensamiento con el de Santo Tomás de Aquino, ni con el de ningún otro doctor de la Iglesia, sino por acudir a los místicos: «pidió a los místicos que lo instruyesen; no lo engañaron».

A la vista del «bergsonismo de hecho» como único horizonte hermenéutico para interpretar el pensamiento del autor en juego, nadie como Garrigou-Lagrange puso a la vista pública las falencias literales del pensamiento de Bergson. Su crítica fue implacable y abarcó prácticamente toda su carrera intelectual, desde Le Sens Commun. La philosophie de l'être et las formules dogmatiques, de 1909 (Garrigou-Lagrange, 1944), hasta sus últimos escritos, de los años 50'. Una de las obras de Garrigou más puntualmente dirigida a deshacer la posición bergsoniana es Le réalisme du principe de finalité, de 1932 (Garrigou-Lagrange, 1949), especialmente su cap. 3. Allí el dominico intenta reivindicar pulcritud terminológica escolástica frente a la confusión «modernista» de Bergson y Le Roy. El catálogo de errores adjudicados al primero es el siguiente:

[la doctrina de la Evolución creadora] admite, en efecto, un devenir sin sujeto, un movimiento sin móvil, un devenir sin causa eficiente, distinto de sí mismo, un devenir sin causa final, conocida por una inteligencia perfecta desde toda la eternidad. Defiende que esta evolución, creadora de sí misma, es ascendente, y por tanto, en ella lo más nace de lo menos, lo más perfecto de lo menos perfecto; rechaza el misterio de la creación, que se armoniza con los principios de la causalidad eficiente, para sustituirlos por el absurdo, tomando como principio de todo: lo más que nace de lo menos sin causa eficiente ni finalidad propiamente dicha. Como alguien dijo, Dios, identificado 
con esta evolución, va de sorpresa en sorpresa, al ver cómo Él mismo deviene sin haberlo previsto (Garrigou-Lagrange, 1949: 66).

Nada más obvio desde el punto de vista del «bergsonismo de hecho». Sin embargo, aun concediendo que la inteligencia no tiene por qué andarse con miramientos a la hora de analizar rigurosamente una doctrina, la excesiva literalidad con que el dominico francés examina la filosofía de Bergson, vuelve por momentos su crítica superficial y hasta naif (algo similar a lo que ocurriría veinticinco años más tarde con el también dominico Santiago Ramírez respecto de Ortega y Gasset).

En síntesis, en lo que respecta a la inteligencia, para Garrigou la posición de Bergson implica la negación de todos los principios fundamentales de la razón, a saber, «los primeros principios de identidad, de razón de ser, de causalidad, de finalidad» (Garrigou-Lagrange, 1949: 62); y con ello, la inmersión en el nihilismo: «significa volver a afirmar que el absurdo radical está situado en el principio de todo» (Garrigou-Lagrange, 1949: 65). Y en lo que hace a la libertad, Garrigou le reprocha al bergsonismo dar lugar al más férreo relativismo y una consecuente reducción de la libertad a la espontaneidad:

¿Qué distinción hacen entre la necesidad y la libertad, cuando reducen la última a una simple espontaneidad? ¿Cómo distinguen absoluta y necesariamente lo verdadero de lo falso, el bien del mal, lo justo de lo injusto? Si desde la eternidad no existe, soberanamente perpetua, la Verdad misma, la Sabiduría misma, no existirán nunca, y jamás la evolución creadora nos dará una norma absoluta para distinguir lo justo de lo injusto, el bien del mal (Garrigou-Lagrange, 1949: 75).

Como conclusión de este primer acápite, vale destacar que la apreciación maritainiana de Bergson no se equipara a la de GarrigouLagrange, siendo la primera más justa y apropiada. La capacidad de Maritain para introducir constantemente los matices necesarios, se constatan en pasajes como este: «Bergson no quiere reducir la libertad a la simple espontaneidad, afirma la libertad de querer humana; y esta sola afirmación de la libertad ha sido para muchos una virtud liberadora» (Maritain, 1983: 91); lo cual exhibe la calidad y profundidad intelectual de la hermenéutica, por encima del entrañable afecto con que naturalmente se tiñe. $\mathrm{Y}$ de este modo, al ser realmente más justa, resulta también más misericordiosa y esperanzadora respecto del pensamiento moderno encarnado particularmente en la figura y obra de Bergson. 


\section{Sertillanges: la vuelta a Tomás de Aquino a través de Bergson}

Toda la resistencia que encontró el autor de La evolución creadora en tomistas como Garrigou-Lagrange, se vio contrarrestada por el decidido apoyo que recibió de otros como Sertillanges, emblema de un neotomismo mucho más receptivo del pensamiento moderno ${ }^{2}$, que empezaría a cristalizar en la Revue thomiste, de la que fuera Secretario de Redacción en los primeros años (Donneaud, 1993). Sobre la primera obra de Bergson -el Essai sur les donées immédiates de la conscience-, en cuyo tercer capítulo aborda la cuestión de la libertad, Sertillanges (1943: 60) opinaba que «desde el inicio se dibuja la curva del pensamiento bergsoniano. Si la conciencia es libertad, es que ya el movimiento general del mundo es libertad». Y, efectivamente, en Bergson -proseguía el estudioso dominico- «la conciencia humana es libre, libre con relación a sus propios antecedentes y libre en relación a toda influencia exterior: Sapiens dominatur astris» (Sertillanges, 1943: 60) ${ }^{3}$. La libertad era un hecho clave para Sertillanges, quien en la segunda parte de Le christianisme et les philosophies (cuyo segundo y último tomo vio la luz el mismo año de la muerte de Bergson, en 1941) calificaba la filosofía bergsoniana de la libertad como «una de las más conformes a la tradición de los cristianos, y más tomista que muchas exposiciones tomistas en esta materia» (Sertillanges, 1941b: 369).

2 «Si hubo un teólogo preocupado de comprender a Bergson, una inteligencia capaz de hacerlo y un corazón de sacerdote ardiente en el deseo de ganar su asentimiento de la fe cristiana, fue el P. A.-D. Sertillanges» (Gilson, 1967: 188; ver Sertillanges, 1941a).

3 En la línea de reivindicación de Bergson por parte de pensadores católicos se encontraba Péguy. En su Note sur M. Bergson et la philosophie bergsonienne, de 1914, Péguy se refería a la difícil encrucijada en que se encontraba la posición de Bergson, «casi tan mal comprendida por sus adversarios como por sus defensores» (Péguy, 1946: 305), en los siguientes términos: «el hombre que ha desbaratado el materialismo tiene en su contra al partido materialista. Está bien. Esto es correcto. El hombre que ha desbaratado el determinismo tiene en su contra al partido determinista. Está bien. Esto es correcto. El hombre que de tal manera ha desbaratado el ateísmo tiene en su contra al partido ateo. Está bien, esto es correcto. Pero el hombre que reintrodujo la libertad tiene en contra al partido radical. El hombre que arrancó el pensamiento francés de la servidumbre alemana tiene en su contra al partido de Acción Francesa. El hombre que reintrodujo la vida espiritual tiene en su contra al partido devoto» (Péguy, 1946: 111). Péguy había sido discípulo directo de Bergson y el testimonio de la incomprensión de su maestro resulta tan atribulado cuanto lúcido: «confieso que no me sorprende el hecho de que los políticos franceses de la vida espiritual hayan conseguido tan prontamente que la burocracia romana condene el pensamiento del Sr. Bergson. Es muy natural que una burocracia, sea la que sea, esté predispuesta contra la filosofía, contra el pensamiento; un pensamiento que (...) se ha elevado, se ha contrapuesto lo más diametralmente posible al hábito, al envejecimiento, a la momificación, a la burocracia y a la muerte» (Péguy, 1946: 109). 
En síntesis, para Sertillanges (1943: 63 y 70) constituiría una «ceguera» acusar a Bergson «de panteísmo, de monismo, de ateísmo disfrazado», cuando precisamente él no ha sido sino afín al tomismo (Sertillanges, 1943: 69). Concretamente, a Sertillanges lo que le parece afín es la noción bergsoniana de intuición - que se delinea de forma acabada ya en la Introduction à la Metaphysique, de 1903- a la noción de libertad en sentido tomístico:

De aquí se sigue que en esto está el tomismo más cerca de Bergson que de ciertos tomistas. En efecto, al analizar estos el acto libre muchas veces consideran el juicio de elección y la misma elección en cuanto voluntaria como causas concurrentes e interferentes, que tendrían por efecto el acto libre. Pero al razonar así caen en el determinismo psicológico, pues convierten el acto en una resultante de fuerzas. Para evitar ese inconveniente hay que decir que en esto depende tanto el juicio de la elección como la elección del juicio. Pero entonces se incurre en círculo vicioso. Para escapar de él se dice: en este caso particular la voluntad desempeña el papel de causa eficiente y el juicio de causa formal; ahora bien, tratándose de causas de diferente orden puede darse la mutua causalidad. Pero olvidan que, de acuerdo con los principios tomistas, la voluntad sólo puede ejercer su acción cuando está determinada por una forma intelectual, que en este caso es el juicio, y más que cuando posee su propia determinación, que le viene de la misma voluntad. No hay forma pues de escapar al círculo vicioso. (...) La única salida consiste en renunciar definitivamente a la disección analítica y al juego de conceptos, y por consiguiente a toda explicación realmente causal. Aquí no interviene el principio de causalidad eficiente, pues se trata del yo tomado en su unidad, en bloque: de él sólo puede salir una espontaneidad pura (...). Tampoco interviene aquí el principio de razón suficiente (...) Ambos principios sólo intervienen posteriormente para explicar analíticamente el acto, tanto desde el punto de vista del mecanismo psicológico, como de la motivación. En una palabra, la verdadera explicación está en el complejo luz-acción, es decir, en ese fondo de mi persona que yace inexplorado e inexplorable (analíticamente) al propio yo (Sertillanges, 1941b: 398-399; véase Sertillanges, 1937; Oesterreicher, 1961: 42-46).

Más allá de la razón o no que tenga Sertillanges, lo que ante todo interesa destacar del pasaje es lo que está reclamando. Y ello consiste en ir al fondo del problema de la libertad, liberándose de fórmulas rígidas, usadas de manera automática; o, en todo caso, reformulándolas de la manera comprensiva y vital que tenían originalmente en la obra del Aquinate. A lo que apunta el reproche de 'circularidad' argumentativa en el habitual análisis tomista de la libertad y la necesidad de eludir el principio de causalidad propuestos por Sertillanges, será abordado más adelan- 
te (ver 4.2). Baste por el momento indicar la intención de Sertillanges en hacer ver que una inadecuada reducción de libertad a racionalidad era rechazada tanto por Tomás como por Bergson:

El acto libre tiene su racionalidad, pues el libre albedrío no es ciego, pero ese acto es inconmensurable con la idea, porque no hay idea capaz de abarcar todo el ámbito de nuestro ser. He aquí una nueva fórmula bergsoniana en que reaparece el equivalente de la desproporción entre el bien universal y el bien particular, que constituye para nosotros el fundamento del libre albedrío (Sertillanges, 1941b: 399).

La valoración conclusiva de Sertillanges respecto de la filosofía de Bergson es tan clara cuanto atenta a hacer justicia del mejor modo posible al «bergsonismo de intención»:

No hay derecho pues a decir que el libre albedrío bergsoniano se basa en el sentimiento o en la voluntad con menosprecio de los derechos de la inteligencia. El mismo Bergson protestó contra semejante interpretación. En carta a nuestro común colega Léon Brunschvicg escribía: 'Yo contrapongo la libertad a la necesidad no como el sentimiento o la voluntad a la inteligencia, sino como la intuición al análisis, como la unidad real, vivida y percibida interiormente a la multiplicidad de vistas que se pueden tomar sobre ella, como la percepción inmediata de la conciencia a la representación mediata más o menos simbólica' (Sertillanges, 1941b: 399).

De todas maneras, lo que estaba en juego - y de algún modo lo sigue estando- era no sólo la justicia para con Bergson, sino también para con Santo Tomás. En otras palabras, era necesario fijarse si por proceder así con Bergson se podía recuperar un Tomás de Aquino que se había vuelto un tanto desconocido.

\section{El esprit de la filosofía bergsoniana conforme a Gilson}

El último caso al que vamos a recurrir en este examen de las posiciones hermenéuticas sobre Bergson por parte del neotomismo, es el de Gilson. Como advertíamos al inicio, la valoración gilsoniana denota cierta componenda entre un «bergsonismo de hecho» y un «bergsonismo de intención»; componenda según la cual la incomprensión sobre el pensamiento de Bergson resultaría equiparada nada más y nada menos que a la que había recaído sobre el pensamiento de Aristóteles hasta la llegada de Tomás de Aquino: «el nuevo Aristóteles no encontró su Santo Tomás de 
Aquino» (Gilson, 1967: 181), es decir, un intérprete cristiano a su medida (Gouhier, 1993: 161) ${ }^{4}$.

Resultan de gran interés las no pocas páginas dedicadas por Gilson en Le philosophe et la théologie, un libro de 1960 de carácter autobiográfico. Son tres los capítulos -VI-VIII- en los que el medievalista se ocupa allí en retratar «el caso Bergson», como lo llama, para hacer una apología de quien había sido también en algún sentido su maestro: «si nosotros, los tomistas, no hemos ayudado en nada a Bergson a comprenderse a sí mismo, por el contrario, él nos ayudó mucho para mejor comprender a Santo Tomás» (Gilson, 1967: 193). Valga remarcar que este punto de vista hermenéutico ya había sido adoptado por Sertillanges, tal como lo manifiesta el mismo Gilson (1967: 193-194):

No tengo conciencia de que en mi interpretación de Santo Tomás de Aquino entre una sola tesis bergsoniana. Por el contrario, estoy persuadido de dos cosas. El P. A. D. Sertillanges escribió un día: "Bergson se equivocó completamente sobre nuestras doctrinas: no le paguemos equivocándonos sobre las suyas". Y esto era cierto, además del ligero matiz de que nos equivocábamos gravemente respecto al sentido de nuestras propias doctrinas. (...) La segunda es otra observación del mismo P. Sertillanges, que tengo el placer de poder aprobar esta vez sin reservas: Bergson, decía incluso, "puede, ciertamente, ayudarnos a comprendernos a nosotros mismos, forzándonos a insistir sobre algunos aspectos de nuestras tesis, que sin él estaríamos tentados de olvidar".

La apuesta, por tanto, de Sertillanges a la valoración positiva de Bergson era doble, y como tal fue asumida por Gilson: 1) no juzgar su filosofía con la misma vara que se juzgaba la propia, esto es, la tomista; 2) percatarse de la ayuda que el filósofo moderno podía prestar al tomismo respecto de la intelección del mismo maestro de la Escuela, Tomás de Aquino. En este sentido, señala un poco más adelante, «la fidelidad de Bergson a lo real concreto nos abría los oídos a cosas que Santo Tomás no cesaba de repetirnos y que, sin embargo, no habíamos aún comprendido» (Gilson, 1967: 194). De este modo, Bergson no era leído según el esquema dual de lo que había dicho y/o la intención de fondo existente en su pensamiento, a fin de valorar su filosofía en sí misma,

4 Para la idea de un bergsonismo cristiano, ver Gouhier (1961: 158-159). Allí Gouhier (1961: 36) también celebra la noción de libertad y hasta cierto punto de liberación que aparece con Bergson, donde la causa resultante de la acción humana es «inconmensurable con sus antecedentes»; si bien Gouhier (1961: 193) reconoce que el autor de La evolución creadora «no ha encontrado la idea de pecado». 
sino según lo que era capaz de inspirar respecto de una comprensión más cabal del Aquinate, y, en último término, de la realidad.

Además de Sertillanges, otro autor que Gilson trae a colación en esas páginas, a fin de obtener una valoración más justa de Bergson, es Péguy. Aunque no pueda decirse que Péguy haya sido un filósofo técnico, ni siquiera un historiador de las ideas, sus intuitivas consideraciones sobre las censuras a Bergson por parte de algunos tomistas (e incluso autoridades eclesiásticas), confirman la advertencia de Sertillanges y Gilson. Péguy percibía cierta ceguera en los censores de Bergson, precisamente para lo que este nuevo pensamiento significaba como acontecimiento histórico en aras de recuperar el dinamismo de las doctrinas del Aquinate. Por eso le parecía una paradoja que se usaran las doctrinas de éste para censurar las de aquél ${ }^{5}$.

Ahora bien, más allá de la inspiración que el pensamiento de Bergson podía brindar al tomismo, en lo que respecta a su valor doctrinal, ¿había para Gilson puntualmente algo que rescatar del mismo? Al respecto, valga reconocer que con «bergsonismo de intención» Maritain no hacía sino señalar que, trascendiendo la simple formulación de hecho, del pensamiento de Bergson cabe hacer algunas deducciones puntuales, las cuales deben valorarse positivamente. ¿Cabría arribar a similar resultado según Gilson? Además de ser sus apreciaciones más generales que puntuales al respecto, no es muy clara la consecuencia que se deriva de las mismas. Gilson es capaz en pocas páginas de darle y a su vez quitarle la razón a Bergson. Sin embargo, ello no supone necesariamente incurrir en contradicción, sino algo de lo que este autor suele con frecuencia usar, y quizá a veces abusar: tal es el matiz. Tómese, por ejemplo, la forma de presentar la apreciación bergsoniana acerca de la inteligencia. En primer lugar, se la valora positivamente:

La filosofía de Bergson estaba tan profundamente impregnada de respeto hacia el conocimiento científico que no se puede, sin inverosimilitud, atribuirle cualquier suerte de desprecio por la inteligencia. En un siglo en el que la verdadera noción de la inteligencia se había perdido, solamente Bergson había emprendido la tarea necesaria, partiendo de la idea que en-

\footnotetext{
5 En la ya citada Note sur M. Bergson et la philosophie bergsonienne, en la que - en palabras de Gilson (1967: 164) - se «conjuraba a los adversarios católicos de Bergson a medir las consecuencias de su actitud», Péguy (1946: 281) decía lo siguiente: «Todo lo que pierde Bergson no lo ganará Santo Tomás: lo volverá a ganar Spencer. Y una vez más Santo Tomás se quedará sin nada. Y sin nadie. Y será lo que era tal y cual era hace 25 o 30 años atrás, antes de que apareciera Bergson: un gran santo del pasado. Respetado, reverenciado, venerado. Sin contacto con el presente, sin lugar, sin la tan singular mordedura, sin el único mordiente que cuenta... (Un gran doctor considerado, celebrado, consagrado, nombrado. Enterrado)».
} 
tonces se tenía de ello, para volver a traerla a sus límites (Gilson, 1967: 145-146).

Ahora bien, todos los elogios que puedan hacerse a una tarea de restauración, no quita al mismo tiempo el deber de hablar de la ruina en cuestión. La inteligencia ciertamente se encontraba en ruinas y, en este sentido, "sería mucho más cierto decir que Bergson ha concebido siempre la investigación filosófica según el modelo de la investigación científica» (Gilson, 1967: 146) y que una de las limitaciones de que adolecía su pensamiento era «una cierta falta de espíritu metafísico» (Gilson, 1967: 201). Esto, ciertamente, no había sido una situación casual: «si la inteligencia se descualifica a sí misma por el conocimiento metafísico, hace falta que el metafísico se vuelva hacia otro lado» (Gilson, 1967: 146; 174176, 201-202 y 208-210). Si nos detuviésemos aquí, resultaría verdaderamente difícil concebir hasta qué punto Gilson piensa realmente que Bergson estaba plenamente capacitado para llevar a buen puerto la predicha restauración. Con todo, la alternancia del signo de valoración en la secuencia no se detiene ahí. En efecto, en la página siguiente el medievalista vuelve a una valoración positiva. Tras citar unas palabras de Bergson, añade: «esta declaración de guerra a la pereza intelectual no es de un enemigo de la inteligencia» (Gilson, 1967: 147; 1980: 207-236).

La impresión que uno se lleva tras leer las páginas que Gilson dedica a Bergson, son la de un profundo reconocimiento por esta especie de nuevo Aristóteles que supo polemizar con las formas más actuales del cientificismo y sus derivados mecanicistas, asociacionistas, deterministas... con las armas que tuvo. Estas eran pobres, pero aun así el resultado no dejó de ser igualmente sorprendente:

La llegada de Bergson al campo de batalla cambió el sentido y las condiciones del combate. Cuando el nuevo campeón entró en la liza, la negación de la metafísica en nombre de la ciencia moderna se vio contrarrestada por las afirmaciones contrarias de una metafísica situada en la prolongación exacta de esta misma ciencia. El positivismo estaba derrotado por un espíritu más positivo aunque el suyo. Al mostrarse más exigente que ellos en materia de ciencia, Bergson acababa de realizar una innovación triunfal en el criticismo y en el cientificismo (Gilson, 1967: 149.

Valoración de estilo parecido es la de otro pensador católico, J. Chevalier, discípulo, amigo y confidente de Bergson, a quien le dedicó un libro y la serie de Entretiens avec Bergson, publicada en 1959. Chevalier ofrece allí el siguiente comentario: 
El único punto débil de su sistema es no haber colocado a la inteligencia en su verdadero lugar, como ha hecho Santo Tomás. Sin duda, por esto es por lo que su obra ha sido incluida en el Índicé. Bergson quedó muy impresionado de ello, creyendo que se trataba en este caso de una consideración dogmática, cuando en realidad no se trata más que de una prevención. Pediremos a Roma que sea retirada esta condenación. Me he esforzado con frecuencia por presentar a Bergson la verdadera tradición de los grandes doctores católicos: si el catolicismo es eso, me respondió Bergson, entonces todos seremos católicos, y yo el primero (Chevalier, 1960: 49).

A diferencia de Maritain, que poco o ningún interés muestra por las condenas o espaldarazos provenientes de las autoridades eclesiásticas sobre la doctrina de Bergson, tanto Gilson como Chevalier prestan mayor atención a este punto. $\mathrm{Y}$ no es que Maritain no haya sido un católico devoto. La diferencia se debe a que es otro el modelo hermenéutico del que este se provee para valorar a Bergson. En cualquier caso, queda claro que para varios de los autores católicos citados - la mayoría de ellos tomistas-, la filosofía de Henri Bergson no tenía por qué caer bajo el conjunto de las doctrinas condenadas en la Pascendi, es decir, no tenía por qué quedar englobada dentro del modernismo. Por el contrario, podía perfectamente ser vista como un aliado de aquello que la Aeterni Patris había propuesto como programa para los años venideros: «la restauración de la doctrina cristiana conforme a la doctrina de Santo Tomás de Aquino». En este sentido, Monseñor Oesterreicher, judío de nacimiento, uno de los autores intelectuales del documento del Concilio Vaticano II Nostra Aetate (sobre la relación de la Iglesia con las religiones nocristianas) y uno de los principales abogados de la reconciliación entre judíos y católicos, también se quejó de la mala interpretación efectuada sobre Bergson por parte de la Iglesia al incluir tres de sus obras en el Index librorum prohibitorum. Cuando «se pudiera pensar que su Dios es "un puro devenir", un "Dios que evoluciona" (...), el pensamiento de Bergson es éste: que Dios no es una cosa, antes bien, [es] "vida incesante, acción, libertad"» (Oesterreicher, 1961: 33). No en vano, «en Las dos fuentes, punto culminante de sus escritos, Bergson puede hablar más completa y claramente; se puede referir a sí mismo como a un "filósofo que sostiene que Dios es una persona"» (Oesterreicher, 1961: 33) ${ }^{7}$.

6 Recuérdese que L'Evolution Créatrice (de 1907), quizá la obra de Bergson más ambiciosa y de más amplio eco, en 1914, cuando había alcanzado ya su $13^{\mathrm{a}}$ edición, fue incluida en el Índice de libros prohibidos.

$7 \quad$ No puede dejar de mencionarse aquí al jesuita francés Joseph de Tonquédec, aunque tomista de menor calado que los anteriores, amigo de Bergson, y quien caracterizara también la filosofía de Bergson como «una luz para la inteligencia de las realidades espirituales» (Tonquédec, 1930: 240). 


\section{E1 carácter intelectual de los deseos más profundos: releyendo al Aquinate a partir de Bergson}

En lo que resta del trabajo, no pretendemos contestar a algunas cuestiones de la filosofía de Bergson desde la de Tomás de Aquino. Lo que nos interesa más bien es aprovechar esta ilustre representación de la metafísica - tal vez una de sus últimas dignas de consideración- para investigar cuál sería la respuesta más interesante que el Aquinate pudiera brindarle a algunas de sus propuestas. Antes que nada, es interesante advertir que, aun inmerso en un tiempo en que la filosofía empezaba ya a mostrar de forma clara sus rasgos declaradamente antimetafísicos, Bergson hace una apología abierta y manifiesta de la metafísica como saber supremo y radical. Sólo a la vista de esta posición puede entenderse y valorarse adecuadamente el pensamiento del francés en su conjunto. Así, su antiintelectualismo no está motivado sino por lo que él considera una genuina defensa de la libertad, creatividad y novedad metafísica, en contra del determinismo de corte cientificista y una rancia filosofía racionalista.

Lo que resta de la exposición se dividirá en dos partes. Primero expondremos, de forma sucinta, la doctrina bergsoniana de la intuición, según la cual lo más radical de la realidad consiste en un deseo que no es de carácter intelectual, y, en consecuencia, carece de finalidad. En segundo lugar, nos ocuparemos de la postura de Tomás de Aquino en este punto, revisando algunos aspectos de cómo concibe él la relación entre inteligencia y voluntad, así como la libertad inherente a la inteligencia en su ordenación constitutiva hacia un fin.

\subsection{La pretensión metafísica de Bergson: una voluntad intuitiva, libre y creativa al margen o por encima de una inteligencia dotada de fines}

Para Bergson, lo preponderante en la realidad, lo que más radicalmente la constituye, no es la inteligencia sino el élan vital. Este impulso vital no es de carácter intelectual, sino intuitivo. La oposición que el francés establece entre inteligencia e intuición no es exactamente simétrica, pues la inteligencia se ubica comparativamente por debajo de la intuición; cuenta con un carácter radicalmente instrumental; se reduce a la esfera práctica. De esta manera, la inteligencia no está radicalmente orientada a sí misma como fin, tal como pensaba Aristóteles, sino a la voluntad que la manda, y a la materia como objeto suyo de transformación (Polo, 2010: 184). La invención, la creatividad es, pues, de carácter intuitivo y pertenece principalmente a la voluntad, que crea y posee dinamismo; la inteligencia, en cambio contempla y, por lo mismo, fija; en sí misma la 
inteligencia es estática. En este sentido, la contemplación no es concebida por Bergson de modo escolástico, es decir, como ocio (otium; sjolè), el cual se traduce en una especulación desinteresada que se demora extáticamente en la contemplación de un ser por sí mismo infinito, fin vital incomprehensible. Por el contrario, Bergson ve la inteligencia según una forma utilitaria. La entiende como una herramienta para resolver necesidades; tiene como objetivo directo los medios para conseguir un fin; no el fin en sí mismo. En este sentido, como ejercicio propio de la inteligencia, más que de contemplación, en el caso de Bergson habría que hablar de una suerte de observación. En efecto, quien observa es aquel capaz de descubrir, en el panorama al que su actividad se aplica, los detalles necesarios que se requieren, o bien para resolver algún problema inherente al campo de observación, o bien para mejorar el funcionamiento del mismo.

Desde luego, en un esbozo tal se revela una concepción racionalista, instrumentalista y pragmatista de la inteligencia, a partir de la cual no hay más que un paso para hacer apología del irracionalismo. Es evidente que tal concepción de una inteligencia tan empobrecida, no alcanza a la filosofía de Tomás de Aquino. Con todo, en lo que respecta al pensamiento de Bergson, lo más interesante de su posición no es la orientación que de él pueda sacarse para justificar fácilmente una crítica al intelectualismo. De otro modo, lo medular y significativo de este autor es lo que señala acerca de la intuición, núcleo central de su propuesta.

$\mathrm{Al}$ leer lo que escribe Bergson acerca de la intuición, notamos antes una preocupación por acentuar el carácter simpático de la intuición y su amplitud, que su ceguera y limitación. En varios pasajes de sus obras, Bergson (1959d: 1032-1033; 1959b: 1076, 1079, 1080, 1099-1100, 1103$1105,1107,1108,1115)$ postula que la intuición es simpatía o contacto con la vida en su radicalidad; contacto del que resulta una compenetración recíproca entre la mente que intuye y la vida intuida, de tal modo que por esa vía se llega al interior de la materia, la vida y la realidad, hasta hacer que uno y otro término coincidan (Bergson, 1959d: 1043). En ello consiste precisamente, en palabras del francés, «entrar en lo que se hace, seguir lo que se mueve, adoptar el devenir que es la vida de las cosas» (Bergson, 1959d: 1045; 1959c: 643). De este modo, si bien la razón intuitiva bergsoniana apremia al borde del inconsciente psicológico y una especie de experiencia cuasi mística de la realidad (Miguez, 1959: 23-24. 29), su ínsito irracionalismo es, como dice Maritain (1983: 23-25), involuntario y secundario.

Más que carencia o imperfección, tal como sugiere la idea de ceguera, la intuición bergsoniana es la plenitud o perfección del instinto o impulso vital (Bergson, 1959c: 581, 583-584, 591-592, 668-669). Ahora 
bien, la intuición no es algo que se dé automática o naturalmente; es un estado pleno de la conciencia difícil de lograr, que consiste precisamente en que la facultad de ver se vuelva «una misma cosa con el acto de querer. Esfuerzo doloroso, que podemos realizar bruscamente violentando la naturaleza, pero no sostener más allá de algunos instantes» (Bergson, 1959c: 643$)^{8}$. Ciertamente, esta voluntad no es cualquier voluntad individual, superficialmente determinada, sino una voluntad común y radical a todas las cosas: «el puro querer, la corriente que atraviesa esta materia comunicándole vida $(.$.$) , cosa que apenas sentimos, que todo lo más$ rozamos al pasar» (Bergson, 1959c: 643, 644) .

Por lo demás, ese querer puro, que es el impulso vital en su instancia plena, no sólo incrementa la vida, sino que lo hace de forma creativa e inventiva; y como tal, de manera novedosa, imprevisible. En este sentido, para Bergson el querer, en su forma más pura o metafísica, no tiene una finalidad dada de antemano - como si la posesión de una finalidad o dirección correspondiente al movimiento del deseo, matara la novedad que le es propia a su ser en cada paso de su despliegue (Bergson, 1959c: 630-631, 638, 644).

Como conclusión de este esbozo de la primacía metafísica abogada por Bergson de la voluntad respecto de la inteligencia, nos gustaría transcribir aquí unas palabras de Maritain, a modo de opinión cualificada cara a emprender el análisis del pensamiento de Tomás de Aquino en torno a las cuestiones vistas:

estoy persuadido de que, si bien la conceptualización bergsoniana debe ser criticada, no obstante, expresa, aunque de manera deficiente, aprehensiones que son profundamente verdaderas, acerca de aquello que en el intelecto es más auténticamente intelectual y es de mayor valor que el raciocinio. (...) El valor de aquello que Bergson opone a la inteligencia, deriva de la inteligencia (Maritain, 1983: 26-27).

Quiérase o no, el modo de pensar expuesto no deja de afectarnos a la hora de interpretar el pensamiento de un autor medieval. Con todo, no pretendemos sostener aquí que nos afecte necesariamente para mal, como un lastre. Por el contrario, pensamos que puede ayudarnos a apreciar

$8 \quad$ En el cap. $3^{\circ}$ del Essai sur les donées immédiates de la conscience (Bergson, 1959a: 179), se indica que el ver en la libertad es idéntico al obrar.

9 «Si la voluntad se pudiera mantener en su estricta ascensión, en su duración, que es también su unidad, si fuera posible la vida pura, que no tuviera ninguna línea descendente, si se mantuviera en su carácter de pura voluntad, entonces sería puramente interior, no tendría exterioridad. Darse cuenta de esto es lo que llama intuición〉 (Polo, 2010: 184). 
con mayor riqueza el pensamiento medieval. Es más, nos parece que el caso Bergson revela que realmente no existe otra manera de leer hoy en día con provecho la filosofía de la Edad Media a no ser desde las verdaderas preocupaciones vigentes. En lo que sigue intentaremos justificar este aserto en relación al pensamiento de Tomás de Aquino.

\subsection{La índole necesariamente intelectual del ser voluntario y libre en Tomás de Aquino}

\section{a. La libertad en la relación inteligencia - fin}

En primer lugar, consideremos el pensamiento de Tomás de Aquino acerca de la relación entre inteligencia y fin, y la aparejada presencia o ausencia de la libertad en esa relación. Tomás afirma sin ambages que un ser es libre fundamentalmente por poseer no cualquier tipo de juicio, sino precisamente uno de carácter racional:

...este juicio no procede del instinto natural en un caso operable particular, sino de cierta comparación de la razón; por eso obra con juicio libre, pudiendo ponerse en movimiento respecto de cosas diversas. En efecto, la razón que se relaciona con realidades contingentes está abierta a los opuestos; tal como se evidencia en los silogismos dialécticos, y las persuasiones retóricas. Ahora bien, los casos operables particulares son ciertas realidades contingentes: por eso, en relación a ellos, el juicio de razón se encuentra ante realidades diversas, y no está determinado a una sola. Por consiguiente, es necesario que el hombre esté dotado de libre albedrío, por el hecho de que es racional (Aquino, 1889: I, q.83, a.1; 1889: I-II, q.13, a.6).

En síntesis, la libertad es fundamentalmente intelectual. En primer lugar, por estar ligada a esa oposición que inhiere al ser racional, según la cual éste se encuentra indeterminado a uno u otro de los opuestos que se le brindan como alternativa. Ratio ad opposita. Con todo, este aspecto, básico, es insuficiente para entender acabadamente la índole intelectual del ser libre. En efecto, la ratio o significación de esta indeterminación o apertura consiste en la posibilidad pasiva de optar, sin tener en cuenta todavía lo optado en sí mismo; a saber, el fin. En otras palabras, en este caso habría libertad por haber razón, pero no todavía por haber elección del fin. O más bien, en este caso el fin resultaría necesariamente elegido. Por ejemplo, el hombre necesariamente quiere la felicidad; no elige no quererla; aunque elija el camino para conseguirla. En contraste, desde un punto de vista activo, el fin no se elige necesariamente: el hombre puede 
elegir querer o no querer ser feliz, en la medida en que se representa de modo activo ese fin como algo a elegir.

Por eso, para Tomás de Aquino, la libertad es acabada o perfectamente intelectual en cuanto trasciende la mencionada oposición racional, y el fin, entonces, comparece para ella. Ahora bien, para que sea posible dicha presentación, debe haber inteligencia del fin: «la voluntad según que quiere algo de forma natural, más responde al intelecto de los principios naturales que a la razón, que se encuentra abierta a los opuestos. Por eso, según esto, [la voluntad] es más potestad intelectual que racional» (Aquino, 1889: I, q.82, a.1). Al intelectualizarse, por encima de su estado germinal de racionalización, la libertad se hace más natural, esto es, mejor imitadora de la naturaleza. Natura ad unum: la voluntad más perfecta es la que imita en su obrar el obrar de la naturaleza, la cual obra por un fin único. De modo semejante, el intelecto de los primeros principios es más importante en Tomás de Aquino que la razón, porque es más simple y agudo. Tal vez no estén tan lejos, en este sentido, la posición de Tomás y la de Bergson: el intelecto tomístico, constitutivamente fiel a la naturaleza, y la intuición bergsoniana, constitutivamente fiel al impulso vital. Sea como fuere, para Tomás de Aquino el hombre que obra libremente por su intelecto, y no meramente por su razón, se adhiere al fin, no ya de modo necesario y pasivo sino libre y activamente. En eso radica, precisamente, la diferencia entre intelecto y naturaleza. En este sentido y sólo en este, la libertad aparece de forma plena como dominium. El hombre entonces juzga de manera reflexiva, y con ello ocurre la posesión de su propio juicio, de todos sus actos en general, y en último término de sí mismo, esto es, de su propio ser:

Toda la razón o núcleo significativo de la libertad depende del modo propio del conocimiento. Pues el apetito se sigue del conocimiento, no siendo el apetito a no ser del bien, lo cual se le propone por virtud cognitiva. (...) Por eso, si el juicio de la facultad cognitiva no está en potestad de alguien, sino que se encuentra determinado por otro, tampoco el apetito estará en su potestad, y, por consiguiente, tampoco el movimiento o la operación en absoluto. Ahora bien, el juicio está en la potestad del que juzga según que puede juzgar sobre su propio juicio; en efecto, de lo que está en nuestra potestad, podemos juzgar. Ahora bien, juzgar de su propio juicio es propio solamente de la razón, que reflexiona sobre su propio acto, y conoce el estado en que se encuentran las realidades sobre las que juzga y por las que juzga. Por lo cual, la raíz de toda libertad está constituida en la razón. Por 
ello, conforme algo se relaciona con la razón, de tal manera se relaciona con el libre albedrío (Aquino, 1973: q.24, a.2) ${ }^{10}$.

Es en el ejercicio de la reflexividad que el hombre revela querer querer la felicidad, es decir, querer el fin en sí mismo. En ese caso, su adhesión al fin no es ya algo necesario, como en el caso de la libertad en estado imperfecto, sin que, al trascender la oposición, si bien nunca deja de existir más que una única alternativa a elegir, sin embargo, esa única alternativa no resulta necesariamente elegida: el dominio de sí establece la posibilidad de elegirla o no. Según Tomás, esta posibilidad de no querer el fin en sí mismo, se traduce en la capacidad que el hombre tiene de representarse fines equivocados como fin último de su vida. Así, el hombre libremente podría rechazar la contemplación como fin último de su vida, y en su lugar optar por la vida de placer, honores o riqueza.

\section{b. ¿Es necesario siempre y en todos los casos entender para querer?}

Una vez atendida la postura de Tomás de que a mayor conocimiento intelectual, mayor libertad, a causa de la profundidad y naturalidad con que dicho conocimiento es capaz de dotar al apetito, a la vista de la posición de Bergson, todavía es preciso determinar si, para el Aquinate, en su obrar la voluntad pudiera omitir en algún momento su natural recurrencia a la inteligencia. Dicho de otro modo, la cuestión es si la actividad intelectual es siempre y en todos los casos anterior por naturaleza a la actividad de la voluntad, la cual derivaría su riqueza, esto es, la riqueza de su querer, invención y creatividad, de las significaciones de las cosas obtenidas intelectualmente. $\mathrm{Al}$ respecto, en primer lugar conviene saber que el medieval establece una conexión necesaria entre la concepción y voli-

10 Que el intelecto o razón sea la causa radical de la libertad, es algo constantemente afirmado por el Aquinate: «Iudicium, non denotat causam materialem, quasi voluntas sit id de quo est iudicium, sed originem libertatis» (Aquino, 1929: d. 24, q. 1, a 3, ad 5); «In solis intellectum habentibus liberum arbitrium invenitur» (Aquino, 1929: Super II Sent., d. 25, q. 1, a 1); «Omne illud quod habet intellectum et rationem, agit libero arbitrio, in quantum scilicet arbitrium eius, quo agit, consequitur apprehensionem intellectus vel rationis» (Aquino, 1982: q.16, a.5); «Unde ubicumque est intellectus, est liberum arbitrium» (Aquino, 1889: I, q.59, a.3); «Radix libertatis est voluntas sicut subiectum, sed sicut causa, est ratio» (Aquino, 1889: I-II, q.17, a.1, ad 2). Por lo demás, este punto parece haber sido olvidado en buena medida por algunos neotomistas, entre los que destaca Cornelio Fabro, quien por momentos parece hacer girar la libertad humana de modo unilateral alrededor de la voluntad, como si de una propiedad exclusiva suya se tratase. A la hora de observar este punto en este gran intérprete de Tomás, no debe pasarse por alto la seducción que el pensamiento de Kierkegaard ejerció sobre él. Es útil al respecto consultar el trabajo de Binetti (2003: 146-156). 
ción particulares del fin último y los razonamientos y voliciones particulares sobre los medios:

...no es menester que alguien piense siempre acerca del último fin, cada vez que apetece u obra algo, sino que la virtud de la primera intención, que es respecto del último fin, permanece en cada apetito de una cosa cualquiera, incluso si no se piensa actualmente del último fin. Así como no se precisa que quien recorre un camino, piense en cada paso sobre su final (Aquino, 1889: I-II, q.1, a.6).

Así, pues, Tomás establece una conexión necesaria entre el apetito o deseo de la bondad misma, y el apetito de tal o cual cosa determinada. Este último apetito depende del primero, el cual tiene por objeto la misma ratio apetibilitatis (la razón misma de «apetecibilidad»). El orden establecido entre estos apetitos es tal a causa de que el deseo de la ratio apetibilitatis es el modo racional en que se realiza la tendencia de la naturaleza hacia su único fin. Este deseo es principal respecto del apetito de elección, que se encuentra mediado por la relación de la razón a los opuestos. Ahora bien, tanto en uno como en otro apetito hay conocimiento. No sólo hay conocimiento en la instancia apetitiva de la ratio, sino también en la instancia primordial de la tendencia originaria al fin, cuyo deseo surge precisamente de un conocimiento primordial (no, pues, propio de la ratio, sino del intellectus):

...en cualquier apetecible pueden considerarse dos cosas, a saber, la misma realidad que se apetece y la razón de 'apetecibilidad', como el deleite o la utilidad o algo similar.

Por tanto, el apetito natural tiende a la misma realidad apetecible sin aprehensión alguna de la razón de 'apetecibilidad' (...). Ahora bien, el apetito superior, que es la voluntad, tiende directamente a la misma razón de 'apetecibilidad' de modo absoluto, así como la voluntad apetece primero y principalmente la misma bondad o la utilidad o algo semejante; en cambio, apetece esta cosa o aquella de manera secundaria, en cuanto es partícipe de la predicha razón: y esto ocurre ya que la naturaleza racional está dotada de tanta capacidad que no le bastaría la inclinación a una cosa determinada, sino que tiene necesidad de muchas y diversas cosas. Por eso, su inclinación consiste en algo común que se encuentra en muchas cosas; y así, por la aprehensión de aquello común, tiende a la realidad apetecible en la que reconoce que existe tal razón de apetecer (Aquino, 1973: q.25, a.1).

Desde luego, esta concepción de inclinación o apetito racional depende, ciertamente, de una manera de entender también el conocimiento. En efecto, la razón de «apetecibilidad», que viene presentada como una 
realidad en sí misma un tanto indeterminada, es objeto formal de la inteligencia: «objeto del intelecto es la misma razón del bien apetecible; ahora bien, el bien apetecible, cuya razón está en el intelecto, es objeto de la voluntad (...). Y por eso el objeto del intelecto es más alto que el objeto de la voluntad» (Aquino, 1889: I, q.82, a.3). Así, una vez que el intelecto aprehende la razón de bondad, la presenta a la voluntad:

[el objeto] del apetito sensible es esta cosa en cuanto es conveniente o deleitable, así como el agua en cuanto conviene al gusto y no en cuanto es agua; en cambio, el objeto propio de la voluntad es el mismo bien de modo absoluto. Y así también difiere la aprehensión del sentido y la del intelecto, pues es propio del sentido aprehender esta cosa teñida de color, en cambio, propio del intelecto es aprehender la naturaleza misma del color (Aquino, 1973: q.25, a.1).

Llegados a este punto, es preciso observar que lo que de verdad está en juego cara a una postura como la de Bergson, es comprender que en Tomás de Aquino este conocimiento de lo universal — de la ratio o naturaleza de una cosa-, con todos los rasgos que le son propios, no va reñido - en lo realmente importante- con la intuición bergsoniana en tanto en cuanto esta misma pretende rescatar lo más puro y enérgico de la realidad. Grosso modo, Bergson (1959a: 133, 156, 56, 112-113, 124, 192) estaría dispuesto a pensar que lo que acaba de decir Tomás de Aquino es propio del funcionamiento de la ciencia. Por su parte, Tomás de Aquino contestaría que él no habla en este caso de forma meramente lógica, sino metafísica. Es decir, aclararía que existe un conocimiento de lo universal que pertenece a la scientia de rebus, no a la mera lógica, en razón de que ese universal es un universal in re-actio intellectus consistit in hoc quod ratio rei intellectae est in intelligente (Aquino, 1889: I, q.82, a.3)-; universal cuya aprehensión, por lo demás, es imprescindible para que haya voluntad. Pues si no se conoce la ratio de las cosas, la voluntad realmente no puede moverse. Tal conocimiento, que busca lo universal en lo singular, es ciertamente el conocimiento metafísico, esto es, la ciencia de lo común real.

De este modo, para que el apetito más radical alcance su objeto, debe cultivarse la ciencia más alta. En este caso, y como pretende Bergson, lo particular está al servicio de lo universal. Sólo que Bergson no admitiría que la metafísica sea una ciencia. Por lo demás, en el caso de la metafísica de Santo Tomás, no se trata de un universal abstracto, sino plenamente real: «la bondad se desea por sí misma, pero esta cosa buena, [se desea] en cuanto participa algo [de la bondad]» (Aquino, 1973: q.25, a.1). 


\section{c. ¿Y qué es más noble: entender o querer?}

Una vez que Tomás deja asentada la anterioridad natural de la inteligencia respecto de la voluntad, es digno de notar que él también considera necesario registrar cierta forma de superioridad de la voluntad respecto de la inteligencia. En la quaestio de appetitu boni, donde expresamente se pregunta cuál de las dos potencias es más alta que la otra: si la voluntad más alta que la inteligencia o a la inversa, Thomas de Aquino (1973: q.22, a.11; 1889: I, q.82, a.3) afirma que, «hablando de modo esencial y absoluto, es más perfecto tener en sí la nobleza de otra cosa que unirse a una realidad noble que existe fuera de sí. Por eso, (...) si se consideraran de modo absoluto (...), el intelecto es esencialmente más eminente que la voluntad». Con todo, a continuación el Aquinate señala que hay una forma (y sólo una), de considerar la voluntad como superior a la inteligencia, a saber, por razón de que, en el caso de las realidades más elevadas, a saber, las divinas, es más eminente unirse a la realidad que tener en sí su nobleza, pues, en este caso, «la nobleza de aquella realidad se posee de modo muy inferior al que aquella realidad tenga en sí misma» (Aquino, 1973: q.22, a.11). En efecto, la voluntad realmente puede llegar a querer o amar y poseer a Dios tal como es en sí mismo; en cambio la inteligencia no puede alcanzar a conocerlo de esa manera. Es decir, en este caso, si ama su objeto, la voluntad lo alcanza; en cambio, por más que la inteligencia intente conocer a Dios como objeto suyo, sólo puede alcanzar una semejanza de él. Por consiguiente, tenemos al menos un caso según el cual, para Thomas de Aquino (1973: q.22, a.11), «querer es más eminente que entender», en la medida en que «querer y amar a Dios [es más eminente] que conocerlo, ya que la misma bondad divina es más perfecta en Dios mismo, en cuanto deseada por la voluntad que el hecho de que sea participada en nosotros en cuanto conocida por el intelecto».

La pregunta que inmediatamente surge de esta exposición, y con la cual se completa la secuencia argumentativa, es si, aun teniendo en cuenta de que en ese caso el querer vaya más allá que el entender, puede llegar a decirse entonces que ese querer no tenga origen en el entender, esto es, que sea ciego, tal como le gustaría apuntar a Bergson al respecto ${ }^{11}$. Ahora bien, para Tomás, aun cuando en ese caso puntual el acto de entender sea más manifiestamente pobre que el acto de amar, siempre y en todos los casos lo querido ha de haber sido de algún modo entendido previa-

11 No obstante, en el Essai sur les donées immédiates de la conscience, en vez de hablar de 'ceguera' de la voluntad respecto de la duración o progreso de la vida, Bergson (1959a: 187-188) señala que ello puede representarse: ciertamente de forma confusa, en la medida en que su relación a la causalidad es de pura posibilidad. 
mente. Que la voluntad llegue más allá que la inteligencia, no debe inducirnos al engaño de pensar que en ese caso sea ciega, puesto que lo que ha motivado a ir más allá es la misma inteligencia, la cual, al captar las semejanzas divinas, ha invitado a la voluntad a lanzarse más allá, hasta la realidad divina misma. En este sentido, cuando Tomás señala que la inteligencia mueve a la voluntad a modo de fin ${ }^{12}$, hay que entender que la mueve no como 'término', es decir, como algo en lo que la voluntad se detiene, sino precisamente a modo de un 'fin' que la voluntad puede atravesar o traspasar hacia el infinito. En efecto, si la inteligencia sólo puede presentar similitudes del bien supremo, y la voluntad alcanza a tocar la realidad misma divina, quiere decir que las similitudes pueden ser traspasadas o superadas por la voluntad, que llega hasta el bien supremo en sí.

Por tanto, incluso en el caso en el que la acción de la voluntad pareciera independizarse de la inteligencia, la inteligencia siempre está fundando la voluntad. Es más, la no-independencia de la voluntad respecto de la inteligencia se revierte incluso en el natural servicio que la voluntad presta a la inteligencia. En efecto, una vez que la voluntad ha conseguido llegar efectivamente más allá, acaece precisamente el progreso o avance de la inteligencia, hacia una intelección más precisa, bien que más laboriosa, de las rationes divinae rei. A esto se refiere Santo Tomás cuando dice que la voluntad mueve todas las otras potencias a modo de causa agen$\mathrm{te}^{13}$.

Por lo demás, nótese de que el hecho de que nada que no haya pasado por la inteligencia pueda ser transferido a la voluntad, nos lleva a plantear de nuevo la cuestión de la relación entre inteligencia y fin. Que Tomás sostenga que la ratio rei entendida se encuentra en el que entiende, ¿equivale, pues, a sostener que, en su acto de entender, el intelecto comprehende o agota la medida inteligible de esa esencia o ratio? En caso de responder afirmativamente a este interrogante, el conocimiento sería considerado desde un punto de vista transitivo -exterior, diría Bergson-, y el fin debería ser tomado como límite (péras). Esa es la lógica con la que procede Bergson cuando considera la inteligencia. En cambio, en caso de negar que el Aquinate sostenga aquello, como corresponde en justicia

12 «Aliquid dicitur movere dupliciter. Uno modo, per modum finis; sicut dicitur quod finis movet efficientem. Et hoc modo intellectus movet voluntatem: quia bonum intellectum est obiectum voluntatis, et movet ipsam ut finis» (Aquino, 1889: I, q.82, a.4).

13 «Alio modo dicitur aliquid movere per modum agentis; sicut alterans movet alteratum, et impellens movet impulsum. Et hoc modo voluntas movet intellectum, et omnes animae vires; ut Anselmus [nota ed. leon.: Eadmerus] dicit in libro de Similitudinibus (cap. II)» (Aquino, 1889: I, q.82, a.4). 
hacerlo, el conocimiento, aun el conocimiento de las cosas inferiores en nobleza a la mente humana, se consideraría desde el punto de vista de la inmanencia - verdaderamente interior-, entendiendo el fin como algo infinito (télos).

A diferencia de Bergson, que plantea que la voluntad tiene fines propios al margen de la inteligencia, Tomás postula que todos los fines de la voluntad - hasta los más radicales y metafísicos- son propiamente intelectuales; los fines concebidos por la inteligencia son los más altos que cabe adquirir a la mente humana. $\mathrm{Y}$ aun cuando la posesión racional respecto de lo más alto sea inferior a la unión volitiva, sin embargo, Tomás claramente sostiene que la posesión racional es la actividad mental y humana más perfecta. A alguno ciertamente podría parecer que Tomás de Aquino fuera en este caso idealista. En efecto, como se ha visto, él afirma sin ambages que, consideradas las cosas en absoluto, es más noble relacionarse con la realidad en tanto que entendida, esto es, in intelligente, que hacerlo con la realidad en sí misma. Sin embargo, en su caso, esto no significa idealismo en absoluto. En efecto, la cosa ut intellecta, para él es la cosa en lo que, estricta y únicamente, tiene de valía última, necesaria y eterna. Se trata, pues, de la presentación o manifestación de la realidad en su estado más actual o perfecto, a saber, la actualización de la ratio rei, esto es, del corazón o núcleo significativo de la realidad, en tanto en cuanto prescinde de las particularidades contingentes. Esto no es idealismo, sino postulación de la realidad del conocimiento metafísico. A diferencia de Bergson, que pretende que el conocimiento sirva a la voluntad, Tomás pretende lo contrario: que la voluntad o unión con la realidad sirva en último término y en todo caso a la más genuina de las acciones humanas, que es la posesión intelectual -la posesión dinámica del misterio de las rationes rerum. Por lo demás, esta posesión intelectual más que asimilación de lo conocido en el cognoscente, en el caso de las realidades más altas que la mente, consiste en lo inverso: la asimilación del cognoscente en lo conocido. Si lo conocido es un fin infinito, el cognoscente puede ir adentrándose cada vez mejor en lo que conoce, a medida que lo va conociendo más. Y en el caso de las realidades inferiores a la mente, más que en un acto de absorción, la posesión intelectual consiste en un acto de llevar las cosas de la potencia al acto, de tal modo de disponerlas a la revelación de su carácter metafísico, esto es, su núcleo significativo universal y necesario, al margen de las particularidades contingentes.

En consecuencia, para Tomás, sin conocimiento no hay plena unión, ni con las realidades superiores, ni con las realidades inferiores. Pues sin conocimiento no hay plena compenetración y consiguiente actualización -de carácter inmanente, no transitivo- de la realidad inferior en la supe- 
rior: conocido en el cognoscente, en el caso de las realidades inferiores, y cognoscente en lo conocido, en el caso de las realidades divinas. Pero este conocimiento que posibilita la unión plena no es cualquier tipo de conocimiento, sino un conocimiento que deja de lado las particularidades contingentes a fin de abrazar la realidad en su núcleo más significativo y pleno.

\section{Conclusión}

A modo de conclusión, vale la pena observar que si para Tomás de Aquino, absolutamente considerado, la inteligencia tiene por objeto lo más simple, abstracto y común, teniendo la voluntad por objeto algo en cierta manera particular, resulta que, de manera condicionada, en lo que se refiere a las realidades supremas, la cuestión se invierte: pues al ir más allá, la voluntad alcanza el bien universal, simple, etc., debiendo la inteligencia contentarse con semejanzas particulares del bien universal. De esta forma, la voluntad termina moviendo a la inteligencia, la cual, respecto de las realidades supremas, se comporta más como ratio que como intellectus ${ }^{14}$. Es en este sentido que debe interpretarse la defensa que Tomás hace del Pseudo-Dionisio en su comentario al De divinis nominibus, cuando este autor neoplatónico sostiene que el bien es superior al ente. Según Tomás, que ello sea así, ocurre non absolute sino conforme a la condición de nuestro ejercicio intelectual, que es de naturaleza racional. Es también en este sentido que debemos entender la asunción y profundización que realiza Tomás de la doctrina aristotélica de que el bien se aparece a cada uno según la naturaleza de cada uno. Para Tomás, «en acciones particulares, el conocimiento [o percepción] que uno tiene del fin depende de la voluntad» de cada uno, no de su carácter (Gallagher, 1994: 65). En otras palabras, la voluntad es la que termina decidiendo qué ha de buscar entenderse concretamente o no. Por esta razón, «cuando un agente toma co-

\footnotetext{
14 «Si vero consideretur voluntas secundum communem rationem sui obiecti, quod est bonum, intellectus autem secundum quod est quaedam res et potentia specialis; sic sub communi ratione boni continetur, velut quoddam speciale, et intellectus ipse, et ipsum intelligere, et obiectum eius, quod est verum, quorum quodlibet est quoddam speciale bonum. Et secundum hoc voluntas est altior intellectu, et potest ipsum movere. Ex his ergo apparet ratio quare hae potentiae suis actibus invicem se includunt, quia intellectus intelligit voluntatem velle, et voluntas vult intellectum intelligere. Et simili ratione bonum continetur sub vero, inquantum est quoddam verum intellectum; et verum continetur sub bono, inquantum est quoddam bonum desiderátum» (Aquino, 1889: I, q.82, a.4). El intelecto entiende que la voluntad quiere, aunque no entiende plenamente lo que la voluntad quiere.
} 
mo su fin lo que no es su verdadero bien, este error del conocimiento procede de la voluntad»(Gallagher, 1994: 65). Esto no contradice lo antes dicho, a saber, que tal querer sea fundamentalmente lúcido, sino que aclara más bien que esa lucidez es originariamente un tanto general, necesitada de mayor concreción. Tal concreción tiene origen en la voluntad. Si Bergson no conoció esta concepción de la libertad, tampoco, por lo visto, su filosofía es una rémora para volver a hacernos con ella; a la cual todavía, una vez repuesta, le cabría seguir aprendiendo de Bergson.

\section{REFERENCIAS}

-Aquino, Th. de (1889). Summa theologiae [1], en Sancti Thomae Aquinatis Opera Omnia (T. 5; Iussu Leonis XIII P. M. edita, cura et studio fratrum praedicatorum). Roma: typographia polyglotta s. c. de propaganda fide.

-Aquino, Th. de (1891). Summa theologiae [I-II], en Sancti Thomae Aquinatis Opera Omnia (T. 6; Iussu Leonis XIII P. M. edita, cura et studio fratrum praedicatorum). Roma: typographia polyglotta s. c. de propaganda fide.

-Aquino, Th. de (1982). Quaestiones disputatae de malo, en Sancti Thomae de Aquino Opera Omnia (T. 23; Iussu Leonis XIII P. M. edita, cura et studio fratrum praedicatorum). Roma: Commissio Leonina - Paris: L. P. J. Vrin.

-Aquino, Th. de (1973). Quaestiones disputatae de veritate, en Sancti Thomae de Aquino Opera Omnia (T. 22, vol. III, fasc. 1; Iussu Leonis XIII P. M. edita, cura et studio fratrum praedicatorum). Roma.

-Aquino, Th. de (1929). Scriptum super libros Sententiarum magistri Petri Lombardi episcopi Parisiensis (T. 2; P. Mandonnet, Ed.). Paris: P. Lethielleux.

-Bergson, H. (1959a). Ensayo sobre los datos inmediatos de la conciencia. En H. Bergson, Obras escogidas (49-206; J. A. Míguez, Trad.). México, D.F.: Aguilar.

-Bergson, H. (1959b). Introducción a la metafísica. En H. Bergson, Obras escogidas (1076-1116; J. A. Míguez, Trad.). México, D.F.: Aguilar.

-Bergson, H. (1959c). La evolución creadora. En H. Bergson, Obras escogidas (433-755; J. A. Míguez, Trad.). México, D.F.: Aguilar.

-Bergson, H. (1959d). La intuición filosófica. En H. Bergson, Obras escogidas (1028-1048; J. A. Míguez, Trad.). México, D.F.: Aguilar.

-Binetti, M. J. (2003). El Itinerario de la Libertad. Un estudio basado en el Diario de Soeren Kierkegaard según la interpretación de Cornelio Fabro. Buenos Aires: CIAFIC.

-Bloy, L. (2007). Diarios (C. Serra, Trad.). Barcelona: Acantilado.

-Chevalier, J. (1960). Conversaciones con Bergson (J. A. Míguez, Trad.) Madrid: Aguilar.

-Donneaud, H. (1993). Les Cinquante premières années de la Revue thomiste. Revue thomiste, 93: 5-25.

-Gallagher, D. (1994). Tomás de Aquino, la voluntad y la Ética a Nicómaco. Tópicos, 6: 59-69. 
-Garrigou-Lagrange, R. (1949). El realismo del principio de finalidad (J. Ferrandis, Trad.). Buenos Aires: Desclée, de Brouwer.

-Garrigou-Lagrange, R. (1944). El sentido común. La filosofía del ser y las fórmulas dogmáticas (O. Derisi y E. Melo, Trad.). Buenos Aires: Desclée, de Brouwer.

-Gilson, É. (1967). El filósofo y la teología (Segunda Edición; G. Torrente Ballester, Trad.). Madrid: Guadarrama.

-Gilson, É. (1980). De Aristóteles a Darwin (y vuelta). Ensayos sobre algunas constantes de la biofilosofía (Segunda Edición; A. Clavería, Trad.). Pamplona: Eunsa.

-Gouhier, H. (1961). Bergson et le Christ des Évangiles. Paris: Librairie Arthème Fayard.

-Gouhier, H. (1993). Etienne Gilson. Trois essais: Bergson. La philosophie chrétienne. L'Art. Paris: Vrin.

-Maritain, J. (1983). De Bergson a Santo Tomás de Aquino. Ensayos de Metafísica y moral (G. Moteau de Buedo, Trad.). Buenos Aires: Club de Lectores.

-Maritain, J. (1986). La philosophie bergsonienne. En J. Maritain et R. Maritain, Oeuvres completes (vol. I: 1906-1920). Paris: Éditions Saint-Paul - Fribourg: Éditions Universitaires Fribourg Suisse.

-Mathieu, V. (1980). Temas y problemas de la filosofía actual (J. Campillo, Trad.). Madrid: Rialp.

-Miguez, J. A. (1959). Prólogo. En H. Bergson, Obras escogidas (11-43; J. A. Míguez, Trad.). México, D.F.: Aguilar.

-Oesterreicher, J. M. (1961). Siete filósofos judios encuentran a Cristo (M. Fuentes Benot, Trad.). Madrid: Aguilar.

-Palacios, J. M. (2006). Prólogo. En H. Bergson, Ensayo sobre los datos inmediatos de la conciencia (J. M. Palacios, Trad.). Salamanca: Sígueme.

-Péguy, Ch. (1946). Nota conjunta sobre Descartes y la filosofía cartesiana (seguida de una nota sobre Bergson y la filosofía bergsoniana) (M. Brugnoli, Trad.). Buenos Aires: Emecé.

-Polo, L. (2010). Conversaciones sobre Bergson acerca del tiempo humano y otros temas. Studia poliana, 12: 179-196.

-Sertillanges, A.-D. (1943). Bergson apologist. En A.-D. Sertillanges, Henri Bergson. Essais et témoignages. Neuchatel: Éditions de la Baconnière.

-Sertillanges, A.-D. (1941a). Bergson et le catholicisme. Paris: Flammarion.

-Sertillanges, A.-D. (1941b). Le christianisme et les philosophies (vol. II: "Les temps moderns"). Paris: Aubier.

-Sertillanges, A.-D. (1937). Le libre arbitre chez St. Thomas et chez Henri Bergson. La Vie Intellectuelle, 25(04): 252-269.

-Tonquédec, J. de (1930). Sur la Philosophie bergsonienne. Paris: Beauchesne.

Sumario: Introducción; 1. Bergsonismo de fait y bergsonismo d'intention según Maritain; 2. Sertillanges: la vuelta a Tomás de Aquino a través de Bergson; 3. El esprit de la filosofía bergsoniana conforme a Gilson; 4. El carácter intelectual de los deseos más profundos: releyendo al Aquinate a partir de Bergson; 4.1. La pretensión metafísica de Bergson: una voluntad intuitiva, libre y creativa al margen o por encima de una inteligencia dotada de fines; 4.2. La índole necesaria- 
mente intelectual del ser libre y voluntario en Tomás de Aquino; Conclusión; Referencias. 